\title{
Effects of new beta-blocking agent (DL-tiprenolol) on conduction within normal and anomalous atrioventricular pathways in Wolff-Parkinson-White syndrome
}

\author{
J. Roelandt, L. Schamroth, and P. G. Hugenholtz \\ From the Thoraxcentre, University Hospital and Medical Faculty, Rotterdam, The Netherlands; \\ and the Baragwanath Hospital and the University of the Witwatersrand, fohannesburg, \\ South Africa
}

The effects of DL-tiprenolol (DU 21445) - a new beta-receptor blocking agent - and atropine on both normal and abnormal conduction pathways in the Wolff-Parkinson-White (WPW) syndrome were studied by means of His bundle electrograms and atrial pacing. It was shown that $D U 21445$ slows conduction through both pathways significantly $(P \leqslant 0.05)$ and has a potential value in the treatment of symptomatic WPW syndrome and perhaps in other types of re-entrant tachycardias.

The effects of atropine were also studied in 2 patients. Atropine did not affect bypass conduction whereas $A V$ conduction velocity was definitely increased.

The study also sheds further light on the mechanism of WPW syndrome. It was found that the bypass had different conducting properties and was most probably a different conducting structure from the normal $A V$ pathway.

Surgical division of the anomalous pathway in the Wolff-Parkinson-White (WPW) syndrome has recently been carried out with some success in a few patients with incapacitating attacks of tachycardia (Cobb et al., 1968; Sealy, Boineau, and Wallace, 1970). Attempts by others have been unsuccessful (Burchell et al., 1967; Cole et al., 1970; Lindsay et al., 1971) and in general the results of this surgical procedure have not, until recently, been particularly encouraging. Conventional medical treatment is therefore still the most widely used method of management, and most generally known antiarrhythmic drugs have, at one time or another, been proposed for the prevention and treatment of the arrhythmias associated with this syndrome.

The administration of beta-receptor blocking agents has been shown to be particularly effective in the prevention and treatment of the attacks of paroxysmal reciprocating tachycardias (Gianelly, Griffin, and Harrison, I967; Gibson and Sowton, 1969). Nevertheless, failures with these agents have occurred in some of the most extensively studied series (Dreifus et al., 1968; Sealy et al., 1970; Lindsay et al., 197I); and this has constituted the Received 9 June 1972. reason for a surgical approach, virtually as a measure of desperation.

Little is known about the conduction properties of, and the influence of drugs on, the anomalous bypass. Only a few studies have dealt with this problem (Roelandt, Draulans, and Roos, 1970; Agha, Myerburg, and Castellanos, 1971; Roelandt et al., 1972). Study of the pharmacological action of drugs on both the normal and the anomalous pathways is now possible through the analysis of $\mathrm{His}$ bundle electrograms and atrial pacing. This method of study may provide objective data for the rational treatment of a symptomatic patient (Wallace et al., I97I).

This paper reports the evaluation of DLtiprenolol (DU 21445) - a new beta-receptor blocking agent - on conduction within the normal and abnormal pathways of the WPW syndrome, by means of His bundle electrograms and atrial pacing.

\footnotetext{
Methods

A multipolar electrode catheter was introduced percutaneously into the femoral vein under local anaesthesia. The catheter was fluoroscopically positioned for the recording of His bundle electro-
} 
grams as described by Scherlag et al. (I969). This bipolar electrogram was derived from two adjacent electrodes on the catheter and led into the AC input of a four-channel Elema directwriting electrocardiograph with an appropriate time constant. Standard lead II and lead VI were recorded simultaneously for reference purposes.

- Paper speeds of 50 and $100 \mathrm{~mm}$ a second were

- used for reproduction and measurement, respectively.

All intervals are expressed in milliseconds (msec) with an accuracy of $\pm 5 \mathrm{msec}$.

In addition, a bipolar electrode catheter was introduced percutaneously and positioned against the lateral wall of the right atrium in the region

- of the sinus node for artificial atrial pacing by means of a suitable variable pacemaker. Great care was taken to ensure proper grounding of all equipment. The right atrium was usually paced at increasing rates until a rate was reached at least as high as that observed during a clinical attack of tachycardia. Recordings for measurements were taken about 45 to 60 seconds after the rate

- was increased, to allow for the attainment of a steady state.

After control measurements, $5 \mathrm{mg}$ DL-tiprenolol (DU 21445) was slowly injected intravenously in Cases I to 4. A second 'pace-run' at nearly identical rate was then repeated after 15 minutes. In Cases 4 and 5 , the effect of atropine administered as a $2 \mathrm{mg}$ intravenous dose 15 minutes after the

FIG. I Case I. Tracings showing the effect of progressively increasing atrial pacing rates in WPW syndrome. The His bundle electrogram $(H B E)$ is recorded simultaneously with leads II and VI. As the rate is increased from 67 to 138 beats a minute, there is a prolongation of the time intervals between the $P$ waves and His spikes (PH intervals) and between the pacemaker artefacts and His spikes (StH intervals) from 75 to 140 msec. At higher pacing rates, the His spike is hidden within the $Q R S$ complex. The intervals between the pace- maker impulse and the delta wave (Std) do not change and remain constant at $130 \mathrm{msec}$. The $S t S$ interval (which indirectly reflects the $Q R S$ duration since the Std interval is constant: $Q R S$ width (StS)-(Std)) lengthens progressively until a pacing rate of 150 beats a minute is reached. Pre-excitation becomes -progressively greater with increasing heart rates because of the decreasing contribution to ventricular excitation via the normal pathway. At pacing rates higher than 162 a minute to 222 a minute, the St $S$ interval remains constant at $280 \mathrm{msec}$, and ventricular activation is effected exclusively by the bypass impulse resulting in a total pre-excitation complex. control 'pace-run' was also studied. In Case 4 the effect of atropine was studied the day before the DU 21445 study.

DL-tiprenolol (DU 21445) is a new beta-blocking agent (Philips-Dulphar N.V. Weesp, The Netherlands) with about the same pharmacological actions as DL-propranolol, but three times more active in reducing heart rate during exercise (Kesteloot et al., 1970).

Statistical analysis of the data obtained with DU 21445 was executed on an IBM 360 computer. The values of the intervals at the pacing rates used for statistical analysis were derived from the basic data by linear interpolation on the scale of paced heart rates. The statistical test used was Wilcoxon's signed rank test for paired differences.

\section{Subjects}

There were 5 patients with WPW syndrome, who volunteered for the study after the procedure had been fully explained to them and their consent obtained.

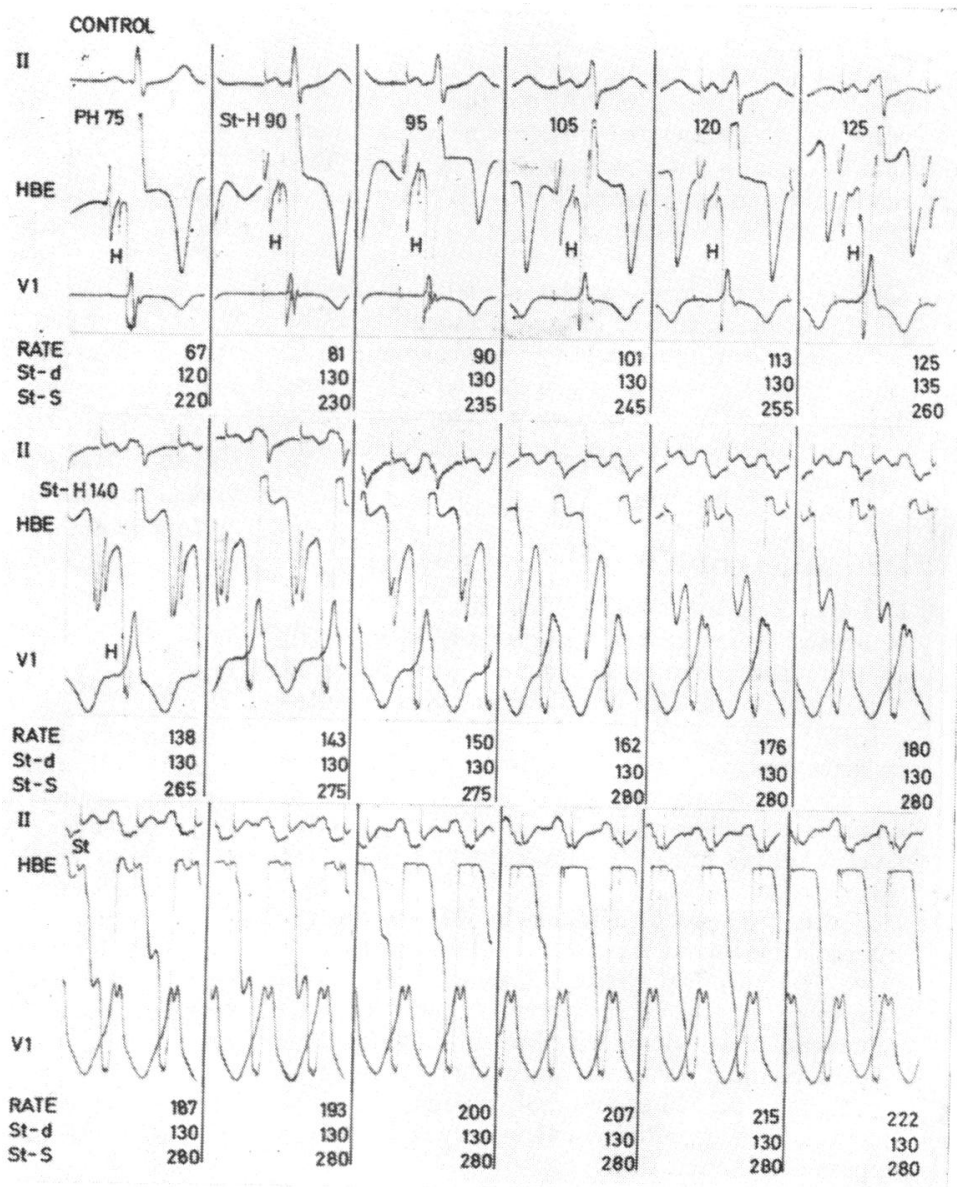


Case I This was a 40-year-old man who suffered from attacks of paroxysmal tachycardia for 18 years. He had experienced at least one attack a week during the preceding two years. These attacks occurred at a rate of about 220 beats a minute and were accompanied by dizziness and faintness. They lasted for periods ranging from ro to 60 minutes. Clinical and laboratory examinations were entirely normal. The basic electrocardiographic pattern revealed sinus rhythm and type A, WPW syndrome.

Case 2 A 17-year-old man had complained of intermittent attacks of rapid heart action during the preceding three years, the frequency of which had increased during the previous few months. Clinical and laboratory examinations were normal. The electrocardiogram showed sinus rhythm and type A, WPW syndrome.

Case 3 This was a 67-year-old man who had occasional attacks of rapid heart action for 50 years. These had become more frequent and were accompanied by angina pectoris during the preceding year. The chest $x$-ray showed slight cardiomegaly. Cine coronary arteriography revealed multiple coronary artery narrowing of more than 50 per cent. The electrocardiogram showed sinus rhythm and a type A, WPW syndrome.

Case 4 A 24-year-old man had 5 attacks of rapid heart action a year during the preceding 5 years associated with praecordial discomfort. Clinical examination was entirely normal. The electrocardiogram showed sinus rhythm and a type A, WPW syndrome.

Case 5 A 26-year-old woman with moderate mitral stenosis had had only two short attacks of tachycardia during pregnancy one year before the study. Her electrocardiogram showed WPW syndrome, type B. His bundle electrograms were recorded during a catheterization for diagnostic purposes.

\section{Definitions of intervals and terms}

PH and StH intervals These are the intervals measured from the beginning of the $P$ wave $(P)$ or from the stimulus artefact $(\mathrm{St})$ to the rapid deflection of the His bundle spike on the intracardiac electrogram. They represent atrial depolarization plus AV nodal conduction. Since changes in atrial conduction time are minimal, changes in these intervals reflect almost exclusively changes in AV nodal conduction time.

Pd interval and Std interval These are the intervals measured from the beginning of the $P$ wave $(P)$ or from the stimulus artefact $(S t)$ to the beginning of the delta wave. These intervals represent atrial depolarization plus anomalous bypass conduction time. Since changes in atrial conduction time are minimal, changes in these intervals reflect almost exclusively changes in bypass conduction time.

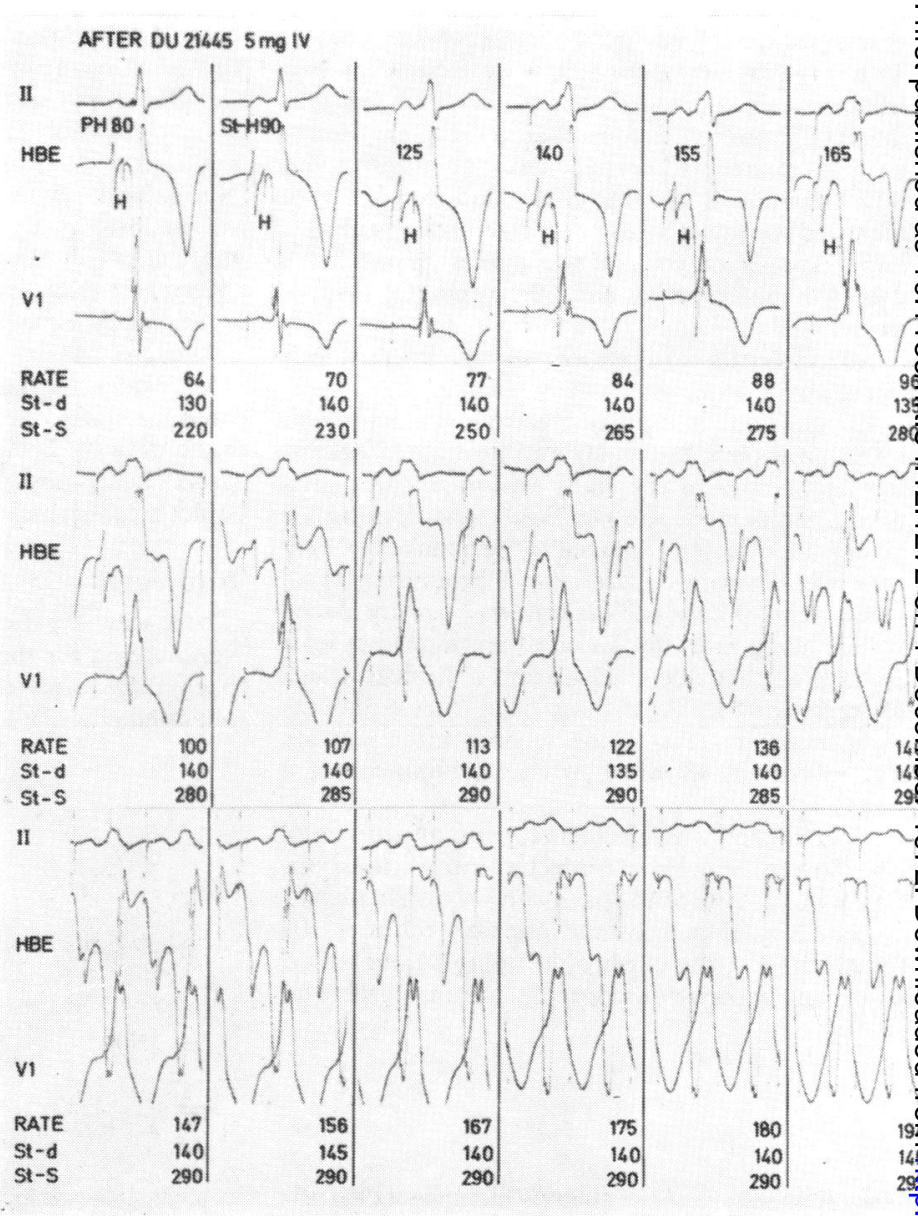

FIG. 2 Case I. Tracings showing the same basic phenomena as in Fig. I. After the injection of $5 \mathrm{mg} D U 21445$ intravenously the $\mathrm{PH}$ and St $\mathrm{H}$ intervals range from 80 to 105 msec at analogous control pacing rates. The Std intervals as well as the StS intervals are also longer compared to control values before the administration of DU 21445.

StS interval This is the interval measured from the stimulus artefact to the end of the QRS complex. When the Std interval remains constant, changes in the StS interval represent changes in total QRS duration or ventricular depolarization.

Normal AV pathway impulse This refers to the impulse conducted through the normal AV pathway: the AV node, bundle of His, and bundlebranches.

Bypass impulse This refers to the impulse conducted through the anomalous pathway or bypass. 
TABLE I Values of measured intervals before and after $5 \mathrm{mg}$ DL-tiprenolol (DU21445)

\begin{tabular}{|c|c|c|c|c|c|c|c|c|c|c|}
\hline \multicolumn{6}{|c|}{ Control } & \multicolumn{5}{|c|}{ After DU $214455 \mathrm{mg} \mathrm{IV}$} \\
\hline \multicolumn{2}{|c|}{$\begin{array}{l}\text { Rate } \\
\text { (b/min) }\end{array}$} & $\begin{array}{l}\text { StH } \\
(\mathrm{msec})\end{array}$ & $\begin{array}{l}\text { Std } \\
(m s e c)\end{array}$ & $\begin{array}{l}\text { StS } \\
(\mathrm{msec})\end{array}$ & $\begin{array}{c}Q R S \\
(m s e c)\end{array}$ & $\begin{array}{l}\text { Rate } \\
\text { (b/min) }\end{array}$ & $\begin{array}{l}\text { StH } \\
(m s e c)\end{array}$ & $\begin{array}{l}\text { Std } \\
(m s e c)\end{array}$ & $\begin{array}{l}\text { StS } \\
(\mathrm{msec})\end{array}$ & $\underset{\text { (mse }}{Q R}$ \\
\hline \multicolumn{11}{|c|}{$\therefore$ Case I } \\
\hline \multirow{4}{*}{$\begin{array}{r}\mathrm{N} \\
\mathrm{Ar}\end{array}$} & 67 & 75 & 120 & 220 & 100 & 64 & 80 & I 30 & 220 & 90 \\
\hline & $8 I$ & 90 & 130 & 230 & 100 & 70 & 90 & 140 & 230 & IIO \\
\hline & 90 & 95 & 130 & 235 & 105 & 77 & 125 & 140 & 250 & 110 \\
\hline & IOI & 105 & 130 & 245 & II 5 & 84 & 140 & 140 & 265 & 125 \\
\hline \multirow[t]{4}{*}{ 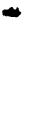 } & 113 & 120 & 130 & 255 & 125 & 88 & I 55 & 140 & 275 & 135 \\
\hline & 125 & 125 & 135 & 260 & 125 & 96 & 165 & I35 & 280 & I 45 \\
\hline & 138 & 140 & 130 & 265 & 135 & 100 & - & 140 & 280 & 140 \\
\hline & 143 & - & 130 & 275 & I45 & 107 & - & 140 & 285 & 145 \\
\hline \multirow[t]{2}{*}{ • } & 150 & - & 130 & 275 & I45 & II3 & - & 140 & 290 & 150 \\
\hline & 162 & - & 130 & 280 & 150 & 122 & - & 135 & 290 & 155 \\
\hline \multirow{3}{*}{$\because$} & I74 & - & 130 & 280 & 150 & 136 & - & I4O & 285 & 145 \\
\hline & 180 & - & 130 & 280 & I5O & I 40 & - & 145 & 290 & 145 \\
\hline & 187 & - & 130 & 280 & 150 & 147 & - & I40 & 290 & 150 \\
\hline \multirow{4}{*}{4} & 193 & - & 130 & 280 & 150 & 156 & - & 145 & 290 & 145 \\
\hline & 200 & - & 130 & 280 & 150 & I67 & - & 140 & 290 & 150 \\
\hline & 207 & - & 130 & 280 & 150 & 175 & - & 140 & 290 & 150 \\
\hline & 215 & - & 130 & 280 & I 50 & 180 & - & 140 & 290 & 150 \\
\hline 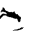 & 222 & - & 130 & 280 & I5O & I94 & - & 145 & 295 & 150 \\
\hline
\end{tabular}

tase 2

NSR 72

IPR 78

, 91

, 102

$150 \quad 240$

22580

80
90

$\begin{array}{ll}270 & 120 \\ 280 & 135\end{array}$

I45 $280 \quad 135$

$\begin{array}{lll}150 & 290 & 140 \\ 150 & 290 & 140\end{array}$

-

, $126 \quad-\quad 150$

$\begin{array}{lll}137 & - & 145 \\ 150 & - & 150\end{array}$

$\begin{array}{rrr}150 & - & 150 \\ 1 & 165-150\end{array}$

$300 \quad 150$

$300 \quad 155$

$300 \quad 150$

$300 \quad 150$

, 170 -

$150 \quad 300$

150

" 191

150

300
305

$\begin{array}{rl}59 & 125 \\ 70 & 140 \\ 78 & 165 \\ 92 & 180 \\ 100 & 200 \\ 111 & - \\ 123 & - \\ 134 & - \\ 147 & - \\ 155 & - \\ 163 & - \\ 172 & - \\ 183 & -\end{array}$

160

$\begin{array}{ll}160 & 235 \\ 160 & 260\end{array}$

$160 \quad 275$

160300

165320

$160 \quad 315$

165320

165320

$160 \quad 320$

$\begin{array}{ll}165 & 320 \\ 170 & 325\end{array}$

165320

$Q R S$

(msec)

Case 3

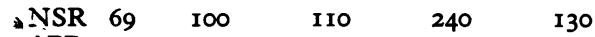

APR 73 IIO

$\begin{array}{lll}\text { I1O } & 240 & 130 \\ 105 & 250 & 145 \\ 110 & 255 & 145 \\ 105 & 255 & 150 \\ 110 & 260 & 150 \\ 110 & 270 & 100 \\ 110 & 275 & 165 \\ 110 & 280 & 170 \\ 110 & 285 & 175 \\ 105 & 290 & 185 \\ 110 & 295 & 185 \\ 110 & 295 & 185 \\ 105 & 295 & 190 \\ 110 & 295 & 185 \\ 110 & 295 & 185 \\ 110 & 295 & 185\end{array}$

$\begin{array}{rllll}63 & 120 & 115 & 245 & 130 \\ 72 & 125 & 115 & 255 & 140 \\ 76 & 135 & 115 & 260 & 145 \\ 82 & 140 & 115 & 265 & 150 \\ 89 & 145 & 115 & 270 & 155 \\ 94 & 150 & 120 & 275 & 155 \\ 100 & 100 & 120 & 280 & 160 \\ 107 & 165 & 115 & 290 & 175 \\ 114 & 190 & 120 & 295 & 175 \\ 121 & - & 120 & 300 & 180 \\ 129 & - & 120 & 305 & 185 \\ 138 & - & 120 & 310 & 190 \\ 144 & - & 115 & 305 & 190 \\ 153 & - & 120 & 310 & 190 \\ 159 & - & 120 & 310 & 190 \\ 165 & - & 125 & 310 & 185 \\ 178 & - & 120 & 310 & 190\end{array}$

Case 4

\begin{tabular}{|c|c|c|c|c|c|c|c|c|c|c|}
\hline NSR & $7 I$ & 120 & 135 & 250 & II5 & 54 & 130 & 150 & 260 & I IO \\
\hline APR & 85 & 145 & 130 & 265 & 135 & 67 & 155 & 150 & 280 & 130 \\
\hline " & 98 & 130 & 135 & 295 & 160 & 90 & 175 & 145 & 295 & 150 \\
\hline & 113 & - & 135 & 305 & I 70 & II 6 & - & 150 & 310 & 160 \\
\hline פ" & 136 & - & 135 & 310 & I75 & 133 & - & 150 & 320 & I 70 \\
\hline " & I59 & - & 135 & 315 & 180 & I5I & - & I 50 & 325 & I75 \\
\hline
\end{tabular}

$\mathrm{NSR}=$ normal sinus rhythm; $\mathrm{APR}=$ atrial pacing rate. 
Pre-excitation fusion complex This refers to a QRS complex resulting from partial anomalous activation and partial normal activation.

Total pre-excitation complex This refers to a QRS complex resulting from complete ventricular activation through the anomalous pathway - a 'pure' delta wave.

\section{Results and analyses}

I) Effect of DU 21445 a) The control parameters The control parameters showing the effects of a progressively increasing atrial pacing rate in Case $I$ are depicted in Fig. I and Table $I$. A progressive increase in atrial pacing rate results in a progressive prolongation of the StH interval from 75 to $140 \mathrm{msec}$. This is due to the increasingly physiological impedance of the AV node to the higher pacing rates. The His spike thus encroaches progressively on the delta wave and is completely hidden within the QRS complex when the heart rate reaches $\mathrm{I} 43$ beats a minute. The Std interval, however, does not change and remains constant at $130 \mathrm{msec}$. This indicates that the bypass conduction time is constant, and that the effective atrial impulse bypasses the AV node to pre-excite the ventricles. Preexcitation becomes progressively greater with increasing heart rates because of the decreasing contribution to ventricular activation through the normal pathway - as a result of increasing delay. This is best seen in lead VI. The QRS complex widens as the StS interval lengthens, while the Std interval remains constant. Furthermore, with pacing rates higher than 162 beats a minute, ventricular activation is effected exclusively by the bypass impulse. This is because ventricular activation is completed before the arrival of the AV nodal impulse, thereby resulting in an exclusive or total pre-excitation complex. This is evident from the fact that the QRS complex does not show any further changes at pacing rates from 162 to 222 beats a minute. The StS interval reflecting QRS duration - also remains constant at these higher pacing rates. All intervals are depicted in Table I, Case $\mathbf{I}$.

b) Test parameters The effect 15 minutes after the intravenous administration of $5 \mathrm{mg}$ DU 21445 is shown in Fig. 2 and Table $I$. The StH intervals or AV nodal transmission times are lengthened when compared to the control values at the same pacing rates, and now range from 80 to $165 \mathrm{msec}$ (compared with 75 to $140 \mathrm{msec}$ ). The Std interval or bypass conduction is also lengthened (by about Io $\mathrm{msec}$ ) and now measures about $140 \mathrm{msec}$. DU 21445 slows conduction through both the normal and anomalous pathways. Total

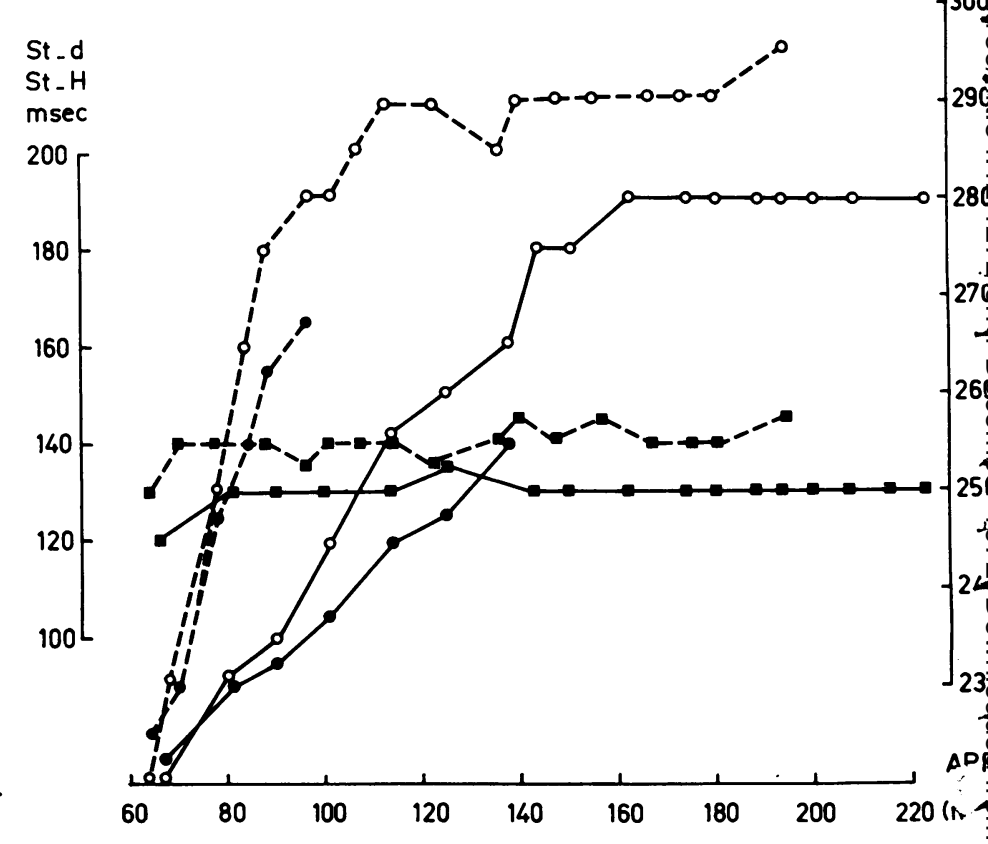

FIG. 3 Case I. Graphic illustration of all intervals represented in Fig. $I$ and 2, and Table I. The diagram shows the behaviour of the different intervals before (solid lines) and after (broken lines) the administration of 5 mg $D U 21445$ at increasing atrial pacing rates $(A P R)$. The Std interval, or conduction through the anomalous bypass, lengthens by about Io msec after DU 21445. The StH interval or $A V$ nodal transmission time is prolonged after beta-blockade. It is obvious that DU 21445 slows conduction both via the normal $A V$ and anomalous pathways. The StS interval, reflecting $Q R S$ duration, parallels $S t H$ prolongation until there is no more contribution to ventricular depolarization by the normal $A V$ impulse. When exclusive bypass depolarization is present, the St $S$ interval parallels the Std interval.

pre-excitation complexes prevail at rates of I 47 to 194 beats a minute. Fig. 3 reflects the different intervals measured before (continuous lines) and after (dashed lines) the administration of $5 \mathrm{mg}$ DU 21445 .

Where the end of the $P$ wave could be 
defined, the interval from the stimulus artefact to the end of the $P$ wave was measured. This represents the atrial activation time. The changes following DU 21445 were not greater than $\pm 5 \mathrm{msec}$. This means that changes in the Std intervals are mainly due to changes in bypass conduction time. The lengthening of the StS interval (reflecting QRS duration changes because of the constant Std interval) parallels the lengthening of the StH intervals at lower heart rates. Once a total pre-excitation complex manifests, the StS intervals and QRS duration remain constant. The $Q R S$ duration is the same both before and after administration of DU 21445, indicating that intraventricular conduction is unaffected. The longer StS interval after DU 21445 is thus merely caused by Std prolongation. The interval changes in Cases 2 and 3 are essentially the same as in Case I (Table I). The QRS duration in Case 2, however, was somewhat longer after DU 21445, probably the result of some intraventricular conduction delay. In Case 4, DU 2I445 was injected the day after the administration of the atropine. The intervals are depicted in Table I. Fig. 4 shows the results diagrammatically. Conduction through the bypass is $15 \mathrm{msec}$ longer after betablockade. Conduction through the normal AV pathway is also prolonged. The QRS duration lengthens with increasing heart rate and parallels the StH lengthening, but is also unaffected by the administration of DU

21445. Table 2 shows the main statistical results of the 4 patients studied. Linear interpolation on the scale of paced heart rates was performed in order to obtain the values of the intervals at the rates used for statistical analysis. With respect to the effects of DU 2I445 on the various intervals, significant differences from premedication values $(P \leqslant 0.05)$ occurred with regard to: (a) the StH intervals at pacing rates of less than 80 beats a minute, (b) the Std intervals at rest or normal sinus rhythm, and at each pacing rate, and (c) the StS intervals at almost each pacing rate (Table 3 ). Changes in resting and maximum pacing heart rates did not reach statistical significance, presumably due to the small sample.

2) Effects of atropine The effects following the administration of $2 \mathrm{mg}$ atropine were studied in Cases 4 and 5 (Table 2), the results - of Case 4 being most extensively shown.

- a) Control parameters The control parameters of Case 4, recorded before administration, are depicted in Fig. 5. As the heart rate increases from 64 to 172 beats a minute, the

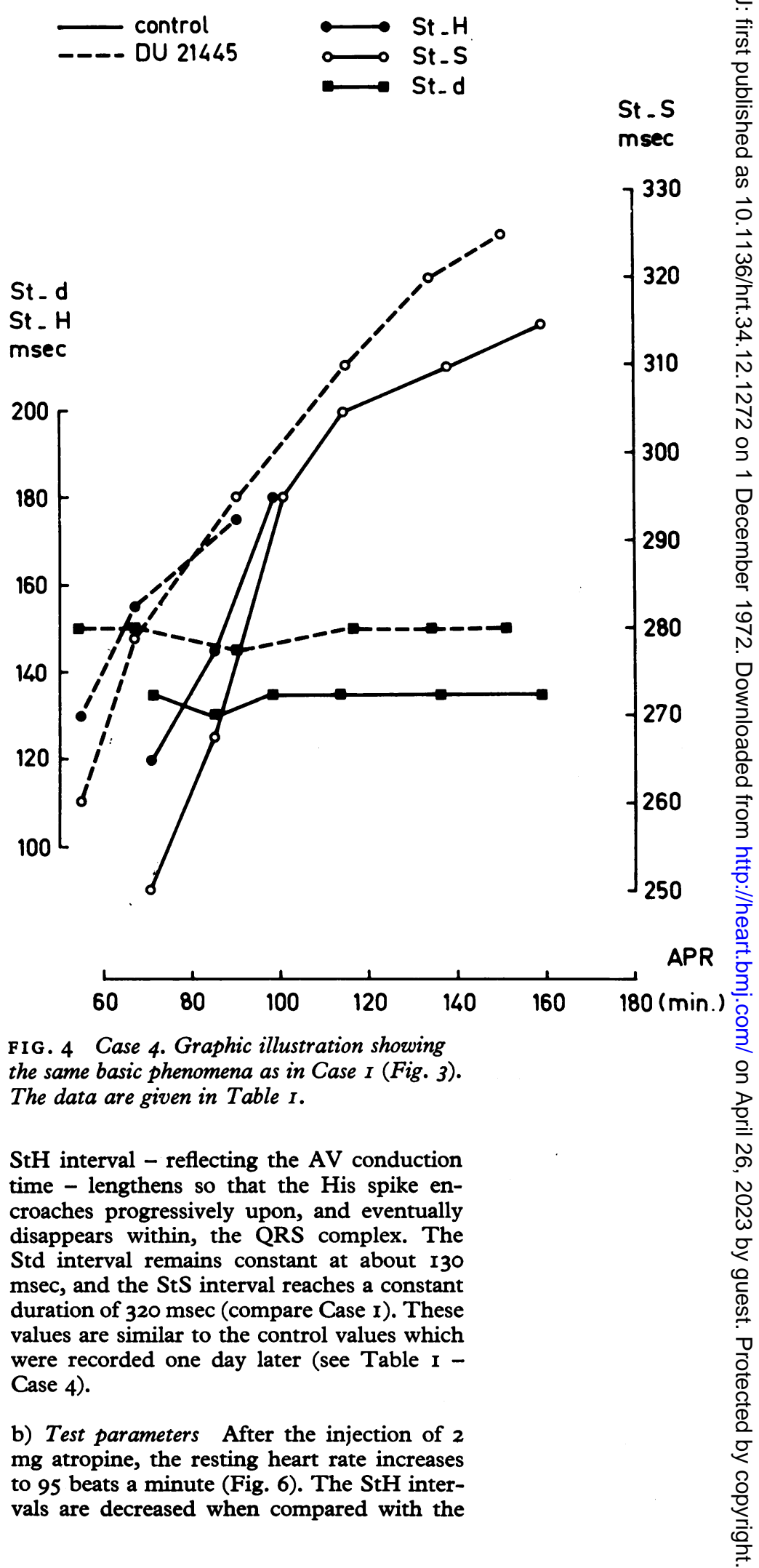


TABLE 2 Values of measured intervals before and after $2 \mathrm{mg}$ atropine IV

\begin{tabular}{|c|c|c|c|c|c|c|c|c|c|}
\hline \multicolumn{5}{|c|}{ Control before atropine } & \multicolumn{5}{|c|}{ After atropine $2 \mathrm{mg} \mathrm{IV}$} \\
\hline $\begin{array}{l}\text { Rate } \\
\text { (b/min) }\end{array}$ & $\begin{array}{l}\text { StH } \\
\text { (msec) }\end{array}$ & $\begin{array}{l}\text { Std } \\
(\mathrm{msec})\end{array}$ & $\begin{array}{l}\text { StS } \\
(\mathrm{msec})\end{array}$ & $\begin{array}{l}Q R S \\
(\mathrm{msec})\end{array}$ & $\begin{array}{l}\text { Rate } \\
\text { (b/min) }\end{array}$ & $\begin{array}{l}\text { StH } \\
(\mathrm{msec})\end{array}$ & $\begin{array}{l}\text { Std } \\
(\mathrm{msec})\end{array}$ & $\begin{array}{l}S t S \\
(m s e c)\end{array}$ & $\begin{array}{c}Q R S \\
\text { (msec) }\end{array}$ \\
\hline \multicolumn{10}{|l|}{ Case 4} \\
\hline $\begin{array}{ll}\text { NSR } & 64 \\
\text { APR } & 81\end{array}$ & $\begin{array}{l}125 \\
150\end{array}$ & $\begin{array}{l}130 \\
135\end{array}$ & $\begin{array}{l}250 \\
270\end{array}$ & $\begin{array}{l}120 \\
135\end{array}$ & $\begin{array}{r}95 \\
107\end{array}$ & $\begin{array}{l}125 \\
145\end{array}$ & $\begin{array}{l}135 \\
130\end{array}$ & $\begin{array}{l}250 \\
265\end{array}$ & $\begin{array}{l}115 \\
135\end{array}$ \\
\hline " 100 & 200 & 130 & 300 & 170 & II 8 & 150 & 130 & 270 & 140 \\
\hline " II7 & - & 130 & 310 & 180 & 134 & 170 & 130 & 285 & 155 \\
\hline و 139 & - & 140 & 320 & 180 & 152 & 190 & 130 & 290 & 160 \\
\hline 172 & 一 & 135 & 320 & 185 & 167 & 200 & 130 & 305 & I 75 \\
\hline \multicolumn{10}{|l|}{ Case 5} \\
\hline 73 & 95 & 100 & 215 & 115 & 102 & 90 & 100 & 210 & 110 \\
\hline 84 & 130 & IIO & 225 & II5 & 113 & 120 & 110 & 225 & II5 \\
\hline 92 & I50 & IIO & 240 & 130 & 125 & 130 & 110 & 235 & 125 \\
\hline IOI & - & II5 & 255 & 140 & 133 & 145 & IIO & 240 & 130 \\
\hline II4 & - & IIO & 260 & 150 & I44 & 160 & IIO & 250 & 140 \\
\hline 126 & - & I IO & 265 & 155 & 158 & - & 105 & 245 & 140 \\
\hline I39 & - & 115 & 270 & 155 & I7I & 一 & 110 & 255 & 145 \\
\hline 150 & - & 110 & 270 & 160 & I79 & 一 & IIO & 260 & 150 \\
\hline 174 & - & I IO & 270 & 160 & & & & & \\
\hline
\end{tabular}

control values recorded at the same heart rates. The His spike is always visible. The atropine results in enhanced AV conduction through the normal AV pathway thereby resulting in lesser degrees of pre-excitation fusion at pacing rates up to 167 beats a minute. There is no change in the Std interval or bypass conduction time. The QRS duration is shortened (when compared to the QRS duration at similar heart rates without atropine). This is due to the diminished contribution of the bypass impulse as a result of the faster AV conduction. The results are depicted diagrammatically in Fig. 7.

\section{Discussion}

The prognosis of the WPW syndrome is usually considered to be benign (Berkman and Lamb, 1968). Nevertheless, sudden and un- expected deaths have, on rare occasion, been reported (Dreifus et al., 1971). Life insurance statistics also show a slightly increased mortality rate in WPW patients (Smith, 1964). The WPW syndrome could, therefore, be viewed as a potentially fatal condition, though this appears to be very rare indeed. However, morbidity secondary to intermittent tachycardias is considerable and treatment directed to the prevention and management of the complicating tachyarrhythmias is thus strongly indicated.

The most attractive basis for the medical treatment of the supraventricular reciprocating tachycardias appears to be the prevention of re-entry by blocking one or both of the AV conducting pathways. The re-entry circuit in the majority of patients with the WPW syndrome, however, includes atrial tissue, the normal AV pathway, ventricular myocardium,

TABLE 3 Average values of heart rate and various intervals at different pacing rates before, and percentage change after, injection of $5 \mathrm{mg} \mathrm{DU} 21445 \mathrm{IV}$ (4 patients)

\begin{tabular}{|c|c|c|c|c|c|c|c|c|c|c|c|}
\hline & \multirow{2}{*}{$\begin{array}{l}\text { Normal } \\
\text { sinus } \\
\text { rhythm }\end{array}$} & \multicolumn{10}{|c|}{ Atrial pacing rate } \\
\hline & & 70 & 80 & 90 & 100 & IIO & $I 20$ & $I 30$ & 140 & 150 & $\begin{array}{l}\text { Max. } \\
\text { heart rate }\end{array}$ \\
\hline $\begin{array}{l}\text { Heart rate before } \mathrm{DU} \\
\% \text { change }\end{array}$ & $\begin{array}{r}70 \\
-14\end{array}$ & 一 & - & - & - & 一 & 一 & 一 & - & 一 & $\begin{array}{l}187 \\
-6\end{array}$ \\
\hline StH before DU & IOI & 102 & 120 & I34 & - & - & - & - & - & - & 172 \\
\hline Std before DU & 128 & 128 & 130 & 130 & 130 & I3I & 132 & 130 & 130 & 130 & I3I \\
\hline$\%$ change & 9 & $\boldsymbol{I I}$ & 9 & 8 & IO & 8 & 8 & 10 & $I I$ & IO & IO \\
\hline StS before DU & 234 & 234 & 247 & 260 & 27 I & 280 & 284 & 290 & 294 & 297 & 299 \\
\hline$\%$ change & 3 & 9 & 10 & IO & 9 & 7 & 7 & 6 & 6 & 5 & 5 \\
\hline
\end{tabular}

Significant differences from premedication values $(P \leqslant 0.05)$ are denoted by italics. 


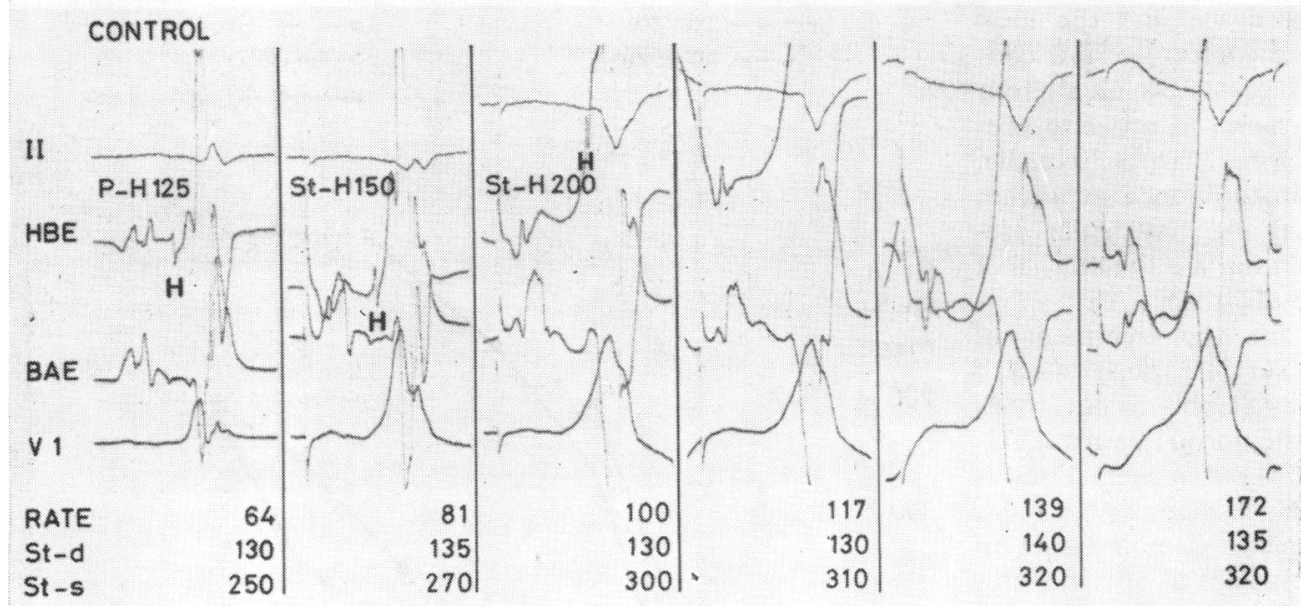

FIG. 5 Case 4. Tracings reflecting the control recordings of the His bundle electrogram (HBE) together with bipolar atrial electrogram $(B A E)$ and leads $I I$ and $V I$ at increasing atrial pacing rates before the intravenous injection of $2 \mathrm{mg}$ atropine. As the pacing rate is increased from 64 to 172 a minute the following effects occur: (i) the His spike $(H)$ disappears in the $Q R S$ complex because of an increase in atrioventricular conduction time, (ii) the Std interval remains relatively (rather) constant, while (iii) the StS interval lengthens from 250 to 320 msec. A 'full-blown' pre-excitation complex is present at a rate of 117 beats a minute.

FIG. 6 Case 4. Tracings reflecting the phenomena after the intravenous administration of $2 \mathrm{mg}$ atropine. The resting heart increases to 95 beats a minute. The StH intervals are decreased compared to control values at the same heart rates. The enhanced AV conduction by atropine results in a more effective ventricular depolarization by the impulse conducted through the normal $A V$ pathway. This results in less obvious pre-excitation complexes at heart rates up to 167 a minute. The His spike $(H)$ stays always visible because of the short $A V$ conduction time. The Std interval, however, is unchanged when compared to the control values.

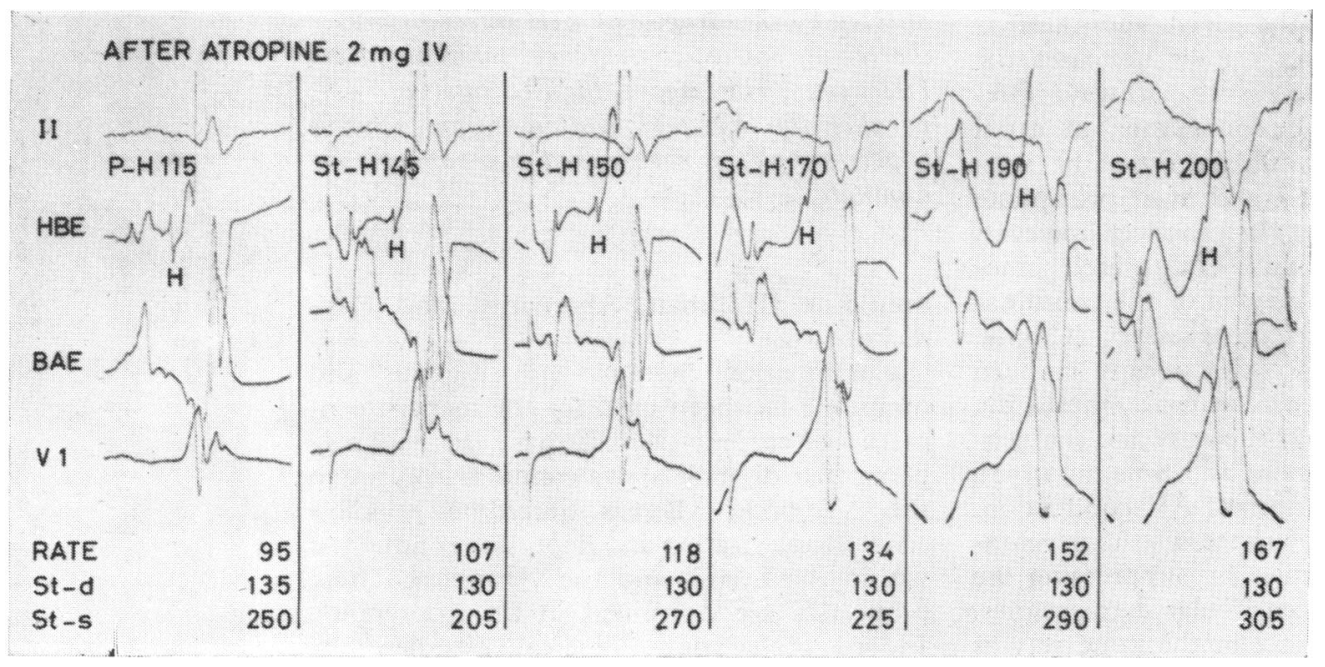


and the anomalous pathway, and the ideal drug should therefore theoretically slow conduction or induce refractoriness at all four of these sites. Furthermore, in order to prevent the attacks of reciprocating tachycardia, the ideal drug should, in addition, also prevent the occurrence of atrial and ventricular premature beats which can initiate the attacks of tachycardia (Durrer et al., 1967).

Other approaches for the treatment of WPW tachycardia are surgical transsection of the anomalous pathway (Cobb et al., 1968; Sealy et al., 1970), or the normal pathway followed by insertion of a pacemaker (Dreifus et al., 1968; Edmonds, Ellison, and Crews, 1969). Induced pacemaker stimuli either in the atria or in the ventricles at specific sites can also be used to make one part of the reentry circuit refractory, as shown experimentally by Moe, Cohen, and Vick (1963). This method was successfully used for the termination of the episodes of reciprocating tachycardia by Durrer et al. (1967), Massumi, Kistin, and Tawakkol (1967), Ryan et al. (I968), Barold and Linhart (1970), and Wellens, Schuilenburg, and Durrer (197I). The principle is analogous to the termination of the reciprocating tachycardias by atrial and/or ventricular extrasystoles which occur spontaneously (Schamroth and Yoshonis, 1969). Though the action on the normal pathway of most antiarrhythmic drugs is well established, there is no information, however, about drug action on the anomalous pathway. While nearly all antiarrhythmic drugs have been tried in patients with symptomatic WPW syndrome, digitalis, quinidine, and procainamide continue to be the most widely used drugs. Digitalis slows AV conduction and reduces the rate of ventricular response during an attack. On the other hand, it shortens the refractory period of the atria, and there is some indirect evidence that it increases the conductivity of the accessory pathway. Theoretically, this can be dangerous in atrial fibrillation since it would increase the ventricular response and could even precipitate ventricular fibrillation. In practice, however, digitalis has been shown useful though sometimes high doses are needed or the combination with other drugs is necessary (Chung, Walsh, and Massie, 1965). Quinidine has been said to prevent impulse re-entry by increasing the refractory period of the atria and the ventricles (Blinder, Burstein, and Smelin, 1952), but it may enhance normal AV conduction. On the other hand, it suppresses the development of the tachycardias by suppressing the initiating atrial and ventricular extrasystoles. Procainamide should act in the same way as

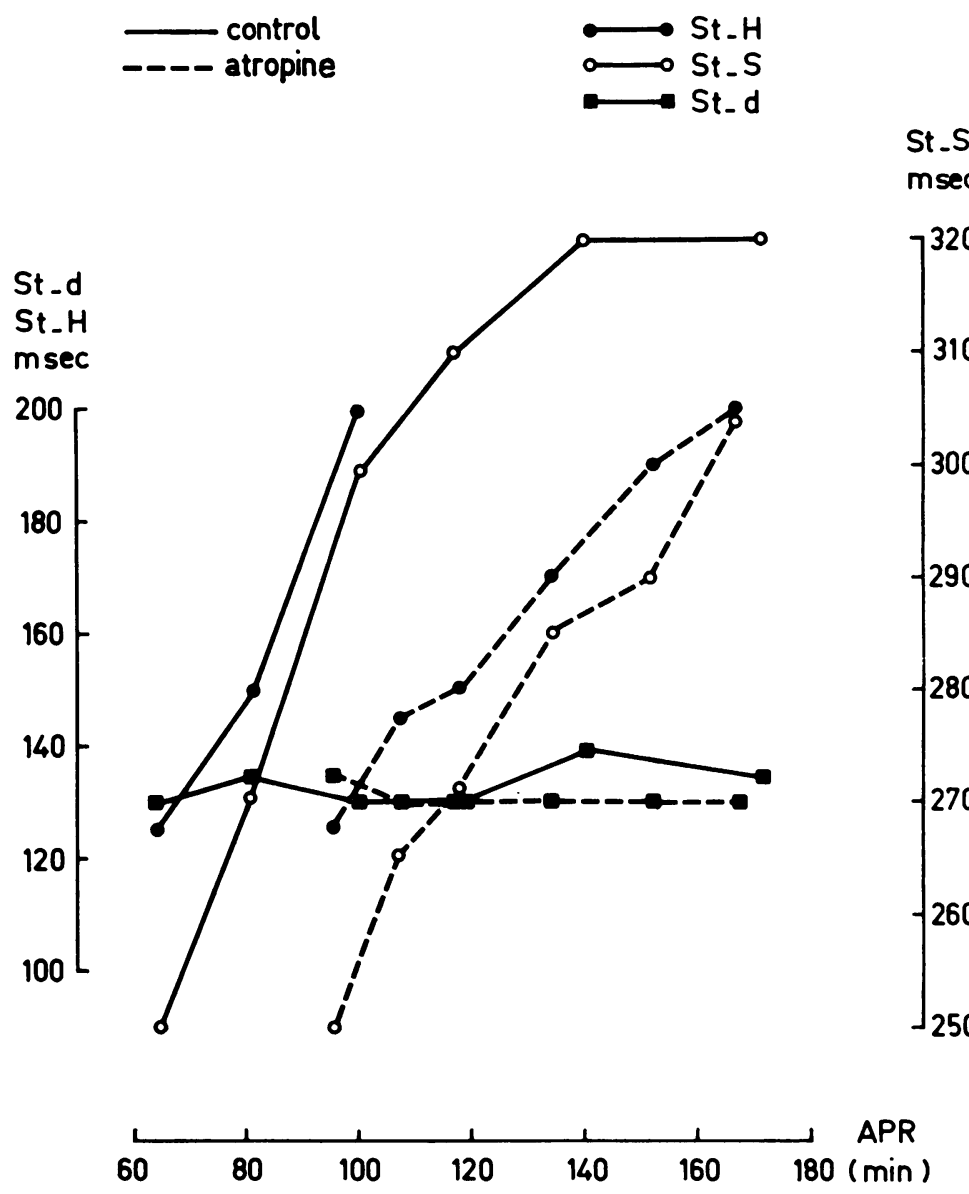

FIG. 7 Case 4. Graphic representations - the results shown in Fig. 5 and 6 and in Table 3. Control values are depicted in continuous lines and values after atropine are depicted in broken lines. The Std interval is the same before and after atropine, and it can thus be concluded that anomalous bypass conduction is not affected by this drug. The StH intervals are shorter in contrast to the longer intervals after $D U$ 21445. Here again, the StS interval parallels the StH prolongation but an exclusive bypass complex is not reached at a rate of 167 a minute.

quinidine (Hoffman, Abernathy, and Haedicke, 1952).

Combination therapy with digitalis and quinidine has been used for the management of the re-entrant tachycardias; the rationale being that digitalis slows conduction through the AV node whereas quinidine prolongs atrial depolarization and depresses conduction within the bypass and the ventricles. These properties are combined in DL-propranolol. Indeed, electrophysiological studies by 
Vaughan Williams (1966) and Davis and Temte (1968) have shown that DL-propranolol has a quinidine-like effect which results in slower myocardial conduction. This is represented by a reduction in the amplitude and rate of rise of the action potential and a prolongation of the effective refractory period. Furthermore, DL-propranolol slows AV conduction by its beta-receptor blocking effect (Berkowitz et al., 1969; Smithen, Balcon, and Sowton, 1971).

Thus, DL-propranolol acts at the four sites of the re-entry pathway and should theoretically be an ideal drug in the management and prevention of the reciprocating tachycardias of the WPW syndrome. There is now ample evidence that beta-blocking agents are usually successful in the prevention and treatment of reciprocating tachycardias of the WPW syndrome (Gianelly et al., 1967; Gibson and Sowton, 1969) and DL-propranolol now appears to be the drug of choice, though failures have been reported (Dreifus et al., 1968; Sealy et al., 1970; Lindsay et al., 1971).

Our study of DL-tiprenolol reveals effects similar to DL-propranolol, though the mechanism of some of the observations with both drugs is not entirely clear. DU 21445 has a beta-receptor blocking effect on AV conduction, and in this respect these are quite comparable to those obtained by Berkowitz et al. (1969) and Smithen et al. (1971) with propranolol. Though in vitro studies with DLpropranolol reveal a depression in the rate of rise of the action potential of Purkinje and muscle fibres, Berkowitz et al. (1969) did not find a prolongation of intraventricular conduction time. In this study too, no QRS prolongation was found both before and after the administration of DL-tiprenolol.

There was, however, an effect on bypass conduction which was consistently prolonged in the four patients whom we studied. This may possibly be due to muscle conduction being more affected than the Purkinje tissue.

In Cases I and 4, it was possible to induce and terminate the attacks of supraventricular tachycardia by properly timed atrial stimuli. After DL-tiprenolol, however, it was impossible to precipitate any tachycardias in Case I, and only short self-terminating attacks of tachycardia could be evoked in Case 4 .

These always terminated with a 'retrograde' $P$ wave which means that re-entry was blocked in the AV node and not in the bypass. Perhaps the drug can also be used with success in other types of re-entry tachycardias.

Atropine has been used for diagnostic purposes in order to diminish or, in some cases, abolish the pre-excitation fusion complex.
This is due to an enhancement of normal AV conduction which thereby results in more complete normal activation. Blinder et al. (1952) reported that the effect of atropine on the bypass was negligible. This was also found in Cases 4 and 5 where the Std interval was unaffected by atropine.

This study also sheds further light on the mechanism of the WPW syndrome. It indicates that the conduction properties of the normal AV nodal pathway and the anomalous pathway are different and unrelated and that the precise electrocardiographic manifestation is dependent upon an entirely unpredictable and at times fortuitous relation of these properties. This indicates not only differing physiological properties but also differing anatomical properties. The latter suggests too that the bypass is probably a different conducting structure.

The authors wish to thank Dr. R. van Strik for his assistance with the statistical work and Dr. A. Floor-Wieringa for helpful comments.

\section{References}

Agha, A. S., Myerburg, R. J., and Castellanos, A., Jr. (197I). Functional properties of accessory bypass tracts as determined by premature atrial stimulation. Circulation, 44, Suppl. II, 62.

Barold, S. S., and Linhart, J. W. (1970). Recent advances in the treatment of ectopic tachycardias by electrical pacing. American fournal of Cardiology, $25,698$.

Berkman, N. L., and Lamb, L. E. (1968). The WolffParkinson-White electrocardiogram: follow-up study of five to twenty-eight years. New England fournal of Medicine, 278, 492.

Berkowitz, W. D., Wit, A. L., Lau, S. H., Steiner, C., and Damato, A. N. (1969). The effects of propranolol on cardiac conduction. Circulation, 40, 855.

Blinder, H., Burstein, J., and Smelin, R. (1952). Drug effects in Wolff-Parkinson-White syndrome. American Heart fournal, 44, 268.

Burchell, J. B., Frye, R. L., Anderson, M. W., and McGoon, D. C. (1967). Atrioventricular and ventricuatrial excitation in Wolff-Parkinson-White syndrome (type B): temporary ablation at surgery. Circulation, 36, 663.

Chung, K. Y., Walsh, T. J., and Massie, E. (1965). Wolff-Parkinson-White syndrome. American Heart fournal, 69, I 16.

Cobb, F. R., Blumenschein, S. D., Sealy, W. C., Boineau, J. P., Wagner, G. S., and Wallace, A. G. (1968). Successful surgical interruption of the bundle of Kent in a patient with the WolffParkinson-White syndrome. Circulation, 38, ror 8.

Cole, J. S., Wills, R. E., Winterscheid, L. C., Reichenbach, D. D., and Blackmon, J. R. (1970). The Wolff-Parkinson-White syndrome: problems in evaluation and surgical therapy. Circulation, 42, III.

Davis, L. D., and Temte, J. V. (1968). Effects of propranolol on the transmembrane potentials of ventricular muscle and Purkinje fibers of the dog. Circulation Research, 22, 66I. 
Dreifus, L. S., Haiat, R., Watanabe, Y., Arriaga, J., and Reitman, N. (197I). Ventricular fibrillation: a possible mechanism of sudden death in patients with Wolff-Parkinson-White syndrome. Circulation, 43, 520.

Dreifus, L. S., Nichols, H., Morse, D., Watanabe, Y., and Truex, R. (1968). Control of recurrent tachycardia of Wolff-Parkinson-White syndrome by surgical ligature of the A-V bundle. Circulation, 38, I030.

Durrer, D., Schoo, L., Schuilenburg, R. M., and Wellens, H. J. J. (1967). The role of premature beats in the initiation and the termination of supraventricular tachycardia in the Wolff-ParkinsonWhite syndrome. Circulation, 36, 644.

Edmonds, J. H., Ellison, R. G., and Crews, T. L. (1969). Surgically induced atrioventricular block as treatment for recurrent atrial tachycardia in Wolff-Parkinson-White syndrome. Circulation, 39, Suppl. I, I05.

Gianelly, R., Griffin, J. R., and Harrison, D. C. (1967). Propranolol in the treatment and prevention of cardiac arrhythmias. Annals of Internal Medicine, 66, 667 .

Gibson, D., and Sowton, E. (1969). The use of betaadrenergic receptor blocking drugs in dysrhythmias. Progress in Cardiovascular Diseases, 12, 16.

Hoffman, I., Abernathy, R. S., and Haedicke, T. A. (I952). Effect of procaine amide on anomalous conduction and paroxysmal tachycardia in a case resembling the Wolff-Parkinson-White syndrome. American Heart fournal, 44, 154.

Kesteloot, H., Sluyts, R., Floor-Wieringa, A., and Van Strik, R. (1970). Effect of beta-receptor blocking drugs on the heart rate during submaximal exercise. European Fournal of Pharmacology, 10, 303.

Lindsay, A. E., Nelson, R. M., Abildskov, J. A., and Wyatt, R. (197I). Attempted surgical division of the pre-excitation pathway in the Wolff-ParkinsonWhite syndrome. American fournal of Cardiology, 28, 581.

Massumi, R. A., Kistin, A. D., and Tawakkol, A. A. (1967). Termination of reciprocating tachycardia by atrial stimulation. Circulation, 36, 637 .

Moe, G. K., Cohen, W., and Vick, R. L. (1963). Experimentally induced paroxysmal A-V nodal tachycardia in the dog. American Heart fournal, 65, 87.
Roelandt, J., Draulans, J., and Roos, J. P. (1970). Functional characteristics of accessory pathways in Wolff-Parkinson-White syndrome (type A) (abstract). Circulation, 42, Suppl. III, 192.

Roelandt, J., Schamroth, L., Draulans, J., and Hugenholtz, P. G. (1972). Functional characteristics of the Wolff-Parkinson-White bypass. American Heart fournal. In the press.

Ryan, G. F., Easley, R. M., Jr., Zaroff, L. I., and Goldstein, S. (I968). Paradoxical use of a demand pacemaker in treatment of supraventricular tachycardia due to the Wolff-Parkinson-White syndrome. Circulation, 38, 1037.

Schamroth, L., and Yoshonis, K. F. (1969). Mechanisms in reciprocal rhythm. American fournal of Cardiology, 24, 224.

Scherlag, B. J., Lau, S. H., Helfant, R. H., Berkowitz, W. D., Stein, E., and Damato, A. N. (1969). Catheter technique for recording His bundle activity in man. Circulation, 39, 13.

Sealy, W. C., Boineau, J. P., and Wallace, A. G. (1970). The identification and division of the bundle of Kent for premature ventricular excitation and supraventricular tachycardia. Surgery, 68, 1009.

Smith, R. F. (1964). The Wolff-Parkinson-White syndrome as an aviation risk. Circulation, 29, 672.

Smithen, C. S., Balcon, R., and Sowton, E. (197I). Use of bundle of His potentials to assess changes in atrioventricular conduction produced by a series of beta-adrenergic blocking agents. British Heart fournal, 33, 955.

Vaughan Williams, E. M. (1966). Mode of action of beta-receptor antagonists on cardiac muscle. American Fournal of Cardiology, 18, 399.

Wallace, A. G., Boineau, J. P., Davidson, R. M., and Sealy, W. C. (I97I). Wolff-Parkinson-White syndrome. A new look. American fournal of Cardiology, 28, 509.

Wellens, H. J. J., Schuilenburg, R. M., and Durrer, D. (197I). Electrical stimulation of the heart in patients with Wolff-Parkinson-White syndrome type A. Circulation, 43, 99.

Requests for reprints to Dr. J. Roelandt, Thoraxcentre, P.O. Box 1738, Rotterdam-3002, The Netherlands. 